\title{
$O$ desafio da pesquisa em enfermagem: $O$ papel do enfermeiro pesquisador
}

Hospital de Transplantes Euryclides de Jesus Zerbini

Letícia de Fatima Lazarini, Deyvid Fernando Mattei da Silva, Aline Corrêa de Araujo, Otavio Monteiro Becker Junior, Elizabeth Akemi Nishio 


\section{Introdução}

É sabido que na área da saúde a pesquisa torna-se uma ferramenta muito importante, transforma o que é empírico em dados e indicadores para análise, fortalece a profissão e dá subsídios para cuidado ao paciente 


\section{Objetivo}

Descrever ações de incentivo à pesquisa para enfermeiros de um hospital público e o papel do enfermeiro pesquisador.

\section{Método}

Pesquisa descritiva, retrospectiva, do tipo relato de experiência. Projeto de investimento em pesquisa, em instituição pública de saúde do Estado de São Paulo. Foram preparadas atividades de incentivo à pesquisa em enfermagem com participação da alta direção, aberto a todos os enfermeiros. Dentre as ações desenvolvidas estavam aulas, palestras e cursos, após o apoio e interesse em desenvolver pesquisa surgiu a necessidade da contratação de um enfermeiro pesquisador para gerenciar as atividades dos enfermeiros interessados em pesquisas. 


\section{Resultados}

Em 1 ano com o enfermeiro pesquisador foram realizados:

- Reuniões mensais de discussão de artigo científico com apoio e participação da diretoria;

- Simpósio de pesquisa científica com premiação aos melhores trabalhos (desenvolvidos na instituição pelos colaboradores);

- Curso de pesquisa clínica aos profissionais (2 edições)- 80 profissionais na primeira turma e 80 profissionais na segunda; 
18 trabalhos enviados a congressos, sendo 6 internacionaisrelacionados a Economia e Avaliação de Tecnologias em Saúde

- Deployment of the ACERTO project in urological surgical patients- AORN, New Orleans

- Economic evaluation of prostate cancer treatment by prostatectomy and HIFU- AORN, New Orleans

- Comparison of patients undergoing new technology for prostate câncer- HTAi, Vancouver

- High-Risk-High-Complexity \& Cost Devices Hospital-Based Management Impact- HTAi, Colonia

- Ação educativa no processo de transplante hepático em um hospital do Estado de São Paulo- ABTO, Coimbra

- Educação permanente no avanço da doação de órgãos em uma organização social de saúde do estado de São Paulo- ABTO, Coimbra 
- Participação em Parecer Técnico Científico (PTC) com a inclusão de nova tecnologia no SUS

- Eventos com embasamento teórico/científico e palestrantes internos e externos;

- Oficinas de Avaliação de Tecnologias em Saúde para os colaboradores

- Criação da Comissão de eventos para auxiliar no conteúdo teórico/científico e a realização de 3 eventos internacionais; 


\section{Projetos:}

24 estão em andamento e 2 em fase de publicação, todos com temas envolvendo a assistência e a prática de cada profissional;

8 profissionais iniciaram o mestrado ou doutorado. 


\section{Conclusão}

$\mathrm{O}$ enfermeiro pesquisador possibilitou o incentivo e o direcionamento das pesquisas realizadas por enfermeiros e viabilizou o caráter científico aos eventos realizados pelo hospital. Foi possível, com o incentivo da alta direção, desenvolver ações que propiciaram estímulo aos profissionais, o que gerou aumento das atividades científicas e do consumo em pesquisa. Com o incentivo ao desenvolvimento das pesquisas observou-se melhora nos indicadores de qualidade e segurança do paciente na instituição. 


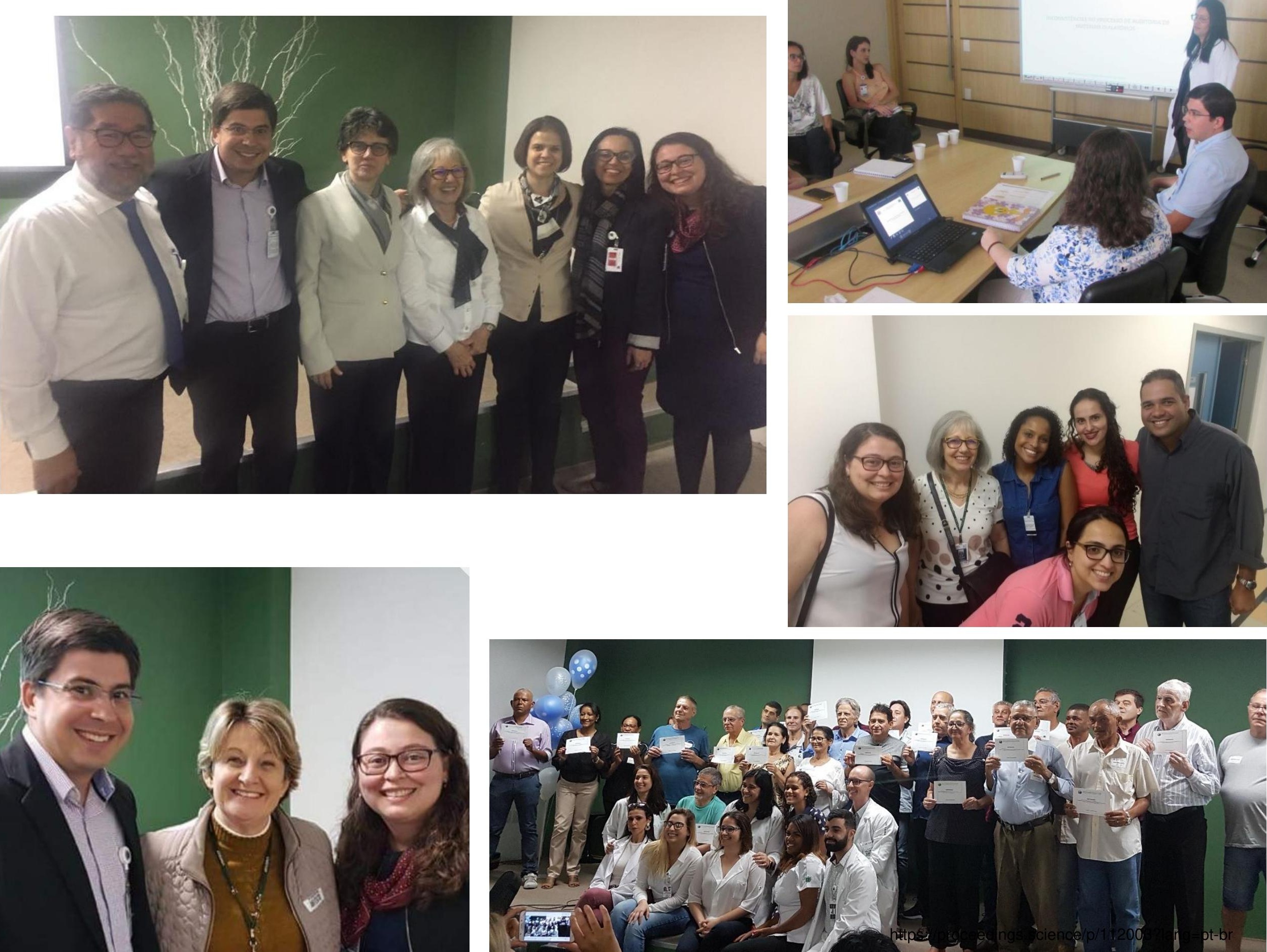




\section{Obrigada!}

\section{leticia.lazarini@htejz.spdm.org.br}

